\title{
Compounds of Complex Halo and Pseudohalo Acids of the Group II B Metals, Part I Etherate, Pyridine and Aniline Compounds of Zn(II)
}

\author{
A. G. Galinos*, J. K. Kouinis, P. V. Ioannou, Th. F. Zafiropoulos, and S. P. Perlepes \\ Department of Inorganic Chemistry, University of Patras, Patras, Greece
}

Z. Naturforsch. 34b, 1101-1106 (1979); received May 11, 1979

Ether, Pyridine, Aniline, Thiocyanate, Zine

The preparation of sixteen new etherate, pyridine and aniline compounds of complex halo and pseudohalo acids of $\mathrm{Zn}(\mathrm{II})$ is reported.

The study of some physical and chemical properties as well as the UV and IR spectra of these compounds are discussed. Tetrahedral structures are proposed for all compounds in the solid state.

\section{Introduction}

Although a large number of salts of the complex anions $\left[\mathrm{M}^{\mathrm{II}} \mathrm{X}_{3}\right]^{-}$and $\left[\mathrm{M}^{\mathrm{II}} \mathrm{X}_{4}\right]^{2-}$ is known, the situation with regard to the corresponding acids is not very clear. The study of these acids is of special interest, since a great number of them is used in certain Friedel-Crafts reactions. The catalytic action of the etherate $\mathrm{HAlCl}_{4} \cdot 2 \mathrm{Et}_{2} \mathrm{O}$ has been studied [1]. The preparation of etherate and pyridine compounds of the acids $\mathrm{HZnCl}_{2} \mathrm{Br}, \mathrm{HZnBr}_{3}$ and $\mathrm{HZnI}_{2} \mathrm{Br}$ has been reported [2-4]. Recently, we prepared and studied the complex compounds $\mathrm{HZnCl}_{3} \cdot 3 \mathrm{An}$, $\mathrm{HZnBr}_{2} \mathrm{Cl} \cdot 3 \mathrm{An}$ and $\mathrm{HZnI}_{2} \mathrm{Cl} \cdot 3 \mathrm{An}$, where $\mathrm{An}=$ aniline [5].

The study of compounds of mixed complex metallohaloacids with pseudohalogens is of some theoretical interest. The isolation of the compounds $\mathrm{HZnCl}_{2}(\mathrm{CSN}) \cdot 2 \mathrm{Et}_{2} \mathrm{O}$ and $\mathrm{HZnBr}_{2}(\mathrm{CSN}) \cdot 2 \mathrm{Et}_{2} \mathrm{O}$ has been achieved in the past [6]**. The etherate, pyridine and aniline compounds of the acids $\mathrm{HInX}_{3} \mathrm{SCN}(\mathrm{X}=\mathrm{Cl}, \mathrm{Br}, \mathrm{I})$ have also been prepared and studied $[7,8]$.

As a continuation of the interest of our laboratory in the complex haloacids and their compounds in this paper we report the preparation, for the first time, of three etherate, five pyridine and eight aniline compounds of complex halo and pseudohalo acids of $\mathrm{Zn}(\mathrm{II})$. Thiocyanate was used as a pseudohalogen.

\section{Experimental}

\section{Reagents}

High purity reagents were used for the preparation of the complex compounds. Diethyl ether was treated as usual for the removal of peroxides and moisture [9]. The organic bases, pyridine and aniline, were doubly distilled under atmospheric pressure.

\section{Preparation of the complexes}

The preparation of the etherate complexes $\mathrm{HZnCl}_{2} \mathrm{I} \cdot 3 \mathrm{Et}_{2} \mathrm{O}(\mathbf{1})$ and $\mathrm{HZnBr}_{2} \mathrm{I} \cdot 3 \mathrm{Et}_{2} \mathrm{O}(2)$ was carried out by the "etherohalogenosis" method [3]. As starting materials anhydrous $\mathrm{ZnCl}_{2}$ and $\mathrm{ZnBr}_{2}$ and an ether solution of $\mathrm{HI}, 0.3 \mathrm{~N}$ were used; the last reagent was in $20 \%$ excess. The experimental temperature was kept at $-50{ }^{\circ} \mathrm{C}$ (mixture of dry ice and acetone). The preparation of $\mathrm{HZnI}_{2}(\mathrm{CSN}) \cdot 3 \mathrm{Et}_{2} \mathrm{O}(3)$ was achieved by a method previously described [7]. The ether solution of HSCN, $0.05 \mathrm{~N}$, was added in $80 \%$ excess. The reaction products $\mathbf{1}, \mathbf{2}$ and 3 , thick oily liquids, were purified by washing with small portions of absolute ether.

For the preparation of the pyridine and aniline compounds the following procedure was used: To small amounts of freshly prepared etherate complex haloacids a slight excess of pyridine or aniline was added dropwise. The reaction was vigorous and exothermic and was accompanied by the evolution of vapours. Immediately after the addition of the base, the whole reaction mixture solidified. The addition of more base caused dissolution of the solid product and the appearance of a clear solution. Subsequently, the reaction vessel was placed in a vacuum desiccator over concentrated sulfuric acid. The final crystalline product was obtained by repeated pumping. The product was washed with small portions of absolute ether and heated to $35^{\circ} \mathrm{C}$ for $15 \mathrm{~min}$.

\section{Analyses}

a) Instruments and apparatus

For the potentiometric determinations of the acidic hydrogen and the organic bases a $\mathrm{pH}$ meter Radiometer Copenhagen NV.-Type PHM 26c and

\footnotetext{
* Reprint requests to Prof. A. G. Galinos.

** Thiocyanate will be indicated as CNS whenever the actual mode of bonding is undetermined. $0340-5087 / 79 / 0800-1101 / \$ 01.00 / 0$
} 
glass and calomel electrodes were employed. In the determinations of the acidic hydrogen in the pyridine and aniline compounds the saturated aqueous solution $\mathrm{KCl}$ of the calomel electrode was replaced by a methanolic one [10]. For the potentiometric determinations of the halogens and the thiocyanate a potentiometer Corning-Eel, model 12 was used with calomel and sulfide electrodes.

b) Analytical procedures

For the quantitative determination of the etherate compounds a solution was prepared by decomposing a definite amount of each compound with water. The acidic hydrogen was determined potentiometrically with a standard $0.1 \mathrm{~N} \mathrm{KOH}$ solution [11a]. The hydrolysis of $\mathrm{Zn}(\mathrm{II})$ was taken into account. Zinc was determined volumetrically with a $0.05 \mathrm{M}$ EDTA solution [11b]. The total halogen was determined volumetrically by the Volhard method [11c] and potentiometrically with a $0.1 \mathrm{~N} \mathrm{AgNO}_{3}$ solution [12]. The iodide ion in the presence of chloride or bromide was determined by the $\mathrm{PdCl}_{2}$ method [1ld]. The sum of iodide and thiocyanate ions as well as each of them in the presence of the other were determined potentiometrically with a $0.1 \mathrm{~N} \mathrm{AgNO}_{3}$ solution [12]. Ether was determined by weight difference.

The acidic hydrogen of the pyridine and aniline compounds was determined potentiometrically with a $0.1 \mathrm{~N} \mathrm{KOH}$ solution, after dissolving them in absolute DMSO [10]. The content of the organic base was determined by dissolving the compound in glacial $\mathrm{CH}_{3} \mathrm{COOH}$ and potentiometric titration with a $0.1 \mathrm{M} \mathrm{HClO}_{4}$ solution in $\mathrm{CH}_{3} \mathrm{COOH}$ or simple titration with $0.1 \mathrm{M} \mathrm{HClO}_{4}$ and Crystal violet as the indicator [13]; to the sample being analyzed were added $5-8 \mathrm{ml}$ of $6 \% \mathrm{Hg}\left(\mathrm{CH}_{3} \mathrm{COO}\right)_{2}$ solution in $\mathrm{CH}_{3} \mathrm{COOH}$. Zinc was determined as described above; a $15 \%$ aqueous solution of $\mathrm{C}_{2} \mathrm{H}_{5} \mathrm{OH}$ was employed as a solvent. The halogens and thiocyanate were determined as described above, the samples being dissolved in $2 \mathrm{~N} \mathrm{HNO}_{3}$. The chloride and bromide ions, the chloride and thiocyanate ions, and the bromide and thiocyanate ions were determined potentiometrically [12].

\section{Stability test for the pyridine and} aniline compounds [4]

A small amount of the compound was dissolved in absolute ethanol. No precipitate appeared by the addition of a $0.5 \%$ ethanolic solution of $\mathrm{AgClO}_{4}$. A slight cloudiness appeared after a few minutes. Dilution with water caused the $\operatorname{Ag}(\mathrm{I})$ halides and AgSCN to precipitate.

\section{Physicochemical measurements}

The m.p. of the pyridine and aniline compounds were obtained in a Büchi 510 apparatus. For the conductivity measurements $10^{-3} \mathrm{M}$ solutions were prepared in $\mathrm{CH}_{3} \mathrm{NO}_{2}$, which was properly pretreated [14]. A conductivity apparatus, Ehrhardt-Metzger
Nachf. type L21, was employed. The cell constant was $\mathrm{C}=1 \mathrm{~cm}^{-1}$ and the measurements were carried out at $25 \pm 0.1{ }^{\circ} \mathrm{C}$. The UV spectra of the pyridine and aniline compounds were taken in a Bausch Lomb-Shimadzu Spectronic 210 UV double beam spectrophotometer with a deuterium lamp. The solvent was spectroscopic quality $\mathrm{C}_{2} \mathrm{H}_{5} \mathrm{OH}$, the concentrations $10^{-5}-10^{-4} \mathrm{M}$ and the region scanned $210-320 \mathrm{~nm}$. The IR spectra of these compounds were recorded in Perkin-Elmer spectrophotometers 457 and 577. The samples were used in the form of $\mathrm{KBr}$ pellets. The spectra covered the region $4000-250 \mathrm{~cm}^{-1}$.

\section{Results and Discussion}

For the preparation of compounds $\mathbf{1}$ and $\mathbf{2}$ a low temperature is required, since at high temperatures ether is cleaved by HI [15]. The etherates fume in air and are insoluble in nonpolar solvents. The pyridine and aniline compounds are formed by the complete replacement of the ether by pyridine or aniline:

$$
\begin{aligned}
& \mathrm{HZnI}_{2}(\mathrm{CSN}) \cdot 3 \mathrm{Et}_{2} \mathrm{O}+3 \mathrm{Py} \stackrel{\mathrm{Py}}{\text { excess }} \\
& \mathrm{HZnI}_{2} \mathrm{SCN} \cdot 3 \mathrm{Py}+3 \mathrm{Et}_{2} \mathrm{O}
\end{aligned}
$$

where $\mathrm{Py}=$ pyridine. The pyridine and aniline compounds are crystalline solids and stable in the air. They are insoluble in nonpolar solvents, somewhat soluble in water and alcohols and soluble in other polar solvents. They dissolve readily in dilute mineral acids.

The analytical results, colors, melting points (uncorrected) and $\Lambda_{M}$ values are given in Table I.

The stability test for the pyridine and aniline compounds lends a strong support to the assumption that all halide ions and the thiocyanate are coordinated to $\mathrm{Zn}(\mathrm{II})$; the new compounds, therefore, are complex compounds and not double salts [4]. The slight cloudiness, appearing after a short time, is attributed to the slight dissociation of the complex ions in ethanol.

From the $\Lambda_{\mathrm{M}}$ values obtained, it is concluded that all pyridine and aniline complexes in nitromethane behave as 1:1 electrolytes [16].

The UV spectra of the pyridine compounds show absorption maxima at 233, 240,245, 250, 257 and $263 \mathrm{~nm}$. These maxima are attributed to $\pi \rightarrow \pi^{*}$ and $n \rightarrow \pi^{*}$ electronic transitions $[17,18]$. The maximum at $290 \mathrm{~nm}$ in the spectra of compounds 4,5 and 8 is very peculiar; it cannot be due to an $n \rightarrow \pi^{*}$ transition $[17,18]$. The UV spectrum of pure aniline 
Table I. Analytical results, colors, m.p. and $\Lambda_{\mathrm{M}}$ values of the new etherate, pyridine and aniline compounds of the complex halo and pseudohalo acids of $\mathrm{Zn}(\mathrm{II})$.

\begin{tabular}{|c|c|c|c|c|c|c|c|c|c|c|c|c|}
\hline No. & Compound & {$[\%]$} & $\begin{array}{l}\text { Acidic } \\
\text { hydro- } \\
\text { gen }\end{array}$ & $\mathrm{Zn}$ & $\mathrm{Cl}$ & $\mathrm{Br}$ & I & $\mathrm{SCN}$ & B & Color & $\begin{array}{l}\mathrm{m} \cdot \mathrm{p} . \\
{\left[{ }^{\circ} \mathrm{C}\right]}\end{array}$ & $\begin{array}{l}\Lambda_{\mathrm{M}^{\mathrm{a}}} \\
{\left[\mathrm{Scm}^{2} \mathrm{~mol}^{-1}\right]}\end{array}$ \\
\hline \multirow[t]{2}{*}{1} & $\mathrm{HZnCl}_{2} \mathrm{I} \cdot 3 \mathrm{Et}_{2} \mathrm{O}$ & Calcd & 0.20 & 13.44 & 14.57 & & 26.08 & & 45.70 & crimson & & \\
\hline & & Found & 0.18 & 13.70 & 14.33 & & 25.60 & & 46.19 & & & \\
\hline \multirow[t]{2}{*}{2} & $\mathrm{HZnBr}_{2} \mathrm{I} \cdot 3 \mathrm{Et}_{2} \mathrm{O}$ & Calcd & 0.17 & 11.36 & & 27.77 & 22.05 & & 38.64 & crimson & & \\
\hline & & Found & 0.16 & 10.99 & & 27.02 & 21.96 & & 39.87 & & & \\
\hline \multirow[t]{2}{*}{3} & $\mathrm{HZnI}_{2}(\mathrm{CSN}) \cdot 3 \mathrm{Et}_{2} \mathrm{O}$ & Calcd & 0.17 & 10.88 & & & 42.31 & 9.66 & 36.98 & orange- & & \\
\hline & & Found & 0.17 & 10.53 & & & 43.18 & 9.86 & 36.29 & red & & \\
\hline \multirow[t]{2}{*}{4} & $\mathrm{HZnCl}_{2} \mathrm{I} \cdot 3 \mathrm{Py}$ & Caled & 0.20 & 13.04 & 14.14 & & 25.30 & & 47.32 & yellow & 110 & 72 \\
\hline & & Found & 0.17 & 13.93 & 14.28 & & 23.15 & & 48.23 & & & \\
\hline \multirow[t]{2}{*}{$\mathbf{5}$} & $\mathrm{HZnBr}_{2} \mathrm{I} \cdot 3 \mathrm{Py}$ & Calcd & 0.17 & 11.07 & & 27.07 & 21.49 & & 40.19 & straw & 117 & 86 \\
\hline & & Found & 0.17 & 11.28 & & 27.72 & 20.45 & & 41.22 & & & \\
\hline \multirow[t]{2}{*}{6} & $\mathrm{HZnCl}_{2} \mathrm{SCN} \cdot 3 \mathrm{Py}$ & Calcd & 0.23 & 15.12 & 16.42 & & & 13.41 & 54.81 & flesh & 191 & 84 \\
\hline & & Found & 0.23 & 16.02 & 16.79 & & & 13.69 & 53.33 & & & \\
\hline \multirow[t]{2}{*}{7} & $\mathrm{HZnBr}_{2} \mathrm{SCN} \cdot 3 \mathrm{Py}$ & Calcd & 0.19 & 12.54 & & 30.69 & & 11.12 & 45.45 & straw & 210 & 79 \\
\hline & & Found & 0.18 & 13.01 & & 31.18 & & 11.31 & 43.06 & & & \\
\hline \multirow[t]{2}{*}{8} & $\mathrm{HZnI}_{2} \mathrm{SCN} \cdot 3 \mathrm{Py}$ & Calcd & 0.16 & 10.63 & & & 41.27 & 9.42 & 38.51 & grey & 182 & 76 \\
\hline & & Found & 0.16 & 11.03 & & & 42.96 & 10.21 & 38.24 & & & \\
\hline \multirow[t]{2}{*}{9} & $\mathrm{HZnCl}_{2} \mathrm{Br} \cdot 3 \mathrm{An}$ & Calcd & 0.20 & 13.17 & 14.28 & 16.09 & & & 56.26 & white & $185 \mathrm{~d}$ & 69 \\
\hline & & Found & 0.18 & 13.38 & 13.74 & 17.28 & & & 54.15 & & & \\
\hline \multirow[t]{2}{*}{10} & $\mathrm{HZnBr}_{3} \cdot 3 \mathrm{An}$ & Caled & 0.17 & 11.17 & & 40.94 & & & 47.72 & pale & $162 \mathrm{~d}$ & 87 \\
\hline & & Found & 0.17 & 10.99 & & 40.46 & & & 47.97 & pink & & \\
\hline \multirow[t]{2}{*}{11} & $\mathrm{HZnI}_{2} \mathrm{Br} \cdot 3 \mathrm{An}$ & Calcd & 0.15 & 9.62 & & 11.76 & 37.35 & & 41.12 & light & $168-$ & 73 \\
\hline & & Found & 0.15 & 9.88 & & 12.34 & 35.11 & & 42.52 & beige & 170 & \\
\hline \multirow[t]{2}{*}{12} & $\mathrm{HZnCl}_{2} \mathrm{I} \cdot 3 \mathrm{An}$ & Calcd & 0.18 & 12.03 & 13.04 & & 23.34 & & 51.40 & whitish- & $150 \mathrm{~d}$ & 81 \\
\hline & & Found & 0.16 & 12.80 & 13.12 & & 23.02 & & 51.05 & yellow & & \\
\hline \multirow[t]{2}{*}{13} & $\mathrm{HZnBr}_{2} \mathrm{I} \cdot 3 \mathrm{An}$ & Calcd & 0.16 & 10.34 & & 25.27 & 20.06 & & 44.17 & yellowish & $162-$ & 68 \\
\hline & & Found & 0.15 & 10.43 & & 26.13 & 19.25 & & 43.79 & & $165 \mathrm{~d}$ & \\
\hline \multirow[t]{2}{*}{14} & $\mathrm{HZnCl}_{2} \mathrm{NCS} \cdot 3 \mathrm{An}$ & Calcd & 0.21 & 13.78 & 14.97 & & & 12.23 & 58.81 & flesh & $238 d$ & 77 \\
\hline & & Found & 0.21 & 14.03 & 15.06 & & & 12.18 & 58.59 & & & \\
\hline \multirow[t]{2}{*}{15} & $\mathrm{HZnBr}_{2} \mathrm{NCS} \cdot 3 \mathrm{An}$ & Caled & 0.18 & 11.61 & & 28.40 & & 10.29 & 49.52 & pale & 245 & 74 \\
\hline & & Found & 0.17 & 12.10 & & 29.04 & & 10.21 & 50.52 & pink & & \\
\hline \multirow[t]{2}{*}{16} & $\mathrm{HZnI}_{2} \mathrm{NCS} \cdot 3 \mathrm{An}$ & Calcd & 0.15 & 9.95 & & & 38.64 & 8.82 & 42.44 & yellow & 217 & 81 \\
\hline & & Found & 0.16 & 10.17 & & & 39.04 & 9.04 & 43.58 & & & \\
\hline
\end{tabular}

$\mathrm{B}=\mathrm{Et}_{2} \mathrm{O}, \mathrm{Py}, \mathrm{An}$. a Values of molar conductance for $10^{-3} \mathrm{M}$ solutions in $\mathrm{CH}_{3} \mathrm{NO}_{2}$ at $25^{\circ} \mathrm{C}$. $\mathrm{d}=$ decomposes.

Table II. IR spectral assignments of some absorption bands of diagnostic value for the pyridine complexes.

\begin{tabular}{|c|c|c|c|c|c|c|c|c|}
\hline Complex & \multirow[t]{2}{*}{$v(\mathrm{C}-\mathrm{N})$} & \multirow[t]{2}{*}{$\delta(\mathrm{N} \mathrm{C} \mathrm{S})$} & \multicolumn{3}{|c|}{$\begin{array}{l}\text { Vibrations of the } \\
\text { pyridine ring }\end{array}$} & \multicolumn{2}{|c|}{$v(\mathrm{Zn}-\mathrm{Cl})_{\mathrm{t}}$} & $v(\mathrm{Zn}-\mathrm{Br})_{\mathrm{t}}$ \\
\hline $\begin{array}{l}4 \\
5\end{array}$ & & & $\begin{array}{l}632 \mathrm{~s} \\
631 \mathrm{~s}\end{array}$ & $\begin{array}{l}420 \mathrm{~s} \\
421 \mathrm{~s}\end{array}$ & $\begin{array}{l}413 \mathrm{sh} \\
411 \mathrm{sh}\end{array}$ & $323 \mathrm{~s}$ & $290 \mathrm{~s}$ & $251 \mathrm{~s}$ \\
\hline 6 & $2078 \mathrm{~s}$ & overlapped by absorption & $638 \mathrm{vs}$ & $422 \mathrm{~s}$ & & $325 \mathrm{~s}$ & $295 \mathrm{~s}$ & \\
\hline 7 & $2078 \mathrm{~s}$ & bands of the coordinated & 638 vs & $422 \mathrm{~s}$ & $418 \mathrm{~s}$ & & & $255 \mathrm{~s}$ \\
\hline $\mathbf{8}$ & $2078 \mathrm{~m}$ & pyridine & $640 \mathrm{~s}$ & $425 \mathrm{~s}$ & $418 \mathrm{~m}$ & & & \\
\hline
\end{tabular}

$\mathrm{s}=$ strong, $\mathrm{sh}=$ shoulder, $\mathrm{m}=$ medium, $\mathrm{vs}=$ very strong.

Table III. IR spectral assignments of some absorption bands of diagnostic value for the aniline complexes.

\begin{tabular}{|c|c|c|c|c|c|c|c|c|c|c|}
\hline Complex & $v(\mathrm{C}-\mathrm{N})$ & $v(\mathrm{C}-\mathrm{S})$ & $\delta(\mathrm{N} \mathrm{C} \mathrm{S})$ & $\nu_{\text {asym }}(\mathrm{N}-\mathrm{H})$ & $v_{\text {sym }}(\mathrm{N}-\mathrm{H})$ & $v(\mathrm{Zn}-\mathrm{A}$ & & $v(\mathrm{Zn}-\mathrm{C}$ & $\mathrm{Cl})_{\mathrm{t}}$ & $v(\mathrm{Zn}-\mathrm{Br})_{\mathrm{t}}$ \\
\hline 9 & & & & $3270 \mathrm{~m}$ & $3225 \mathrm{~m}$ & $400 \mathrm{sh}$ & $357 \mathrm{~s}$ & $290 \mathrm{~s}$ & $274 \mathrm{sh}$ & $<250$ \\
\hline 10 & & & & $3263 \mathrm{~m}$ & $3220 \mathrm{~m}$ & $399 \mathrm{sh}$ & $355 \mathrm{~s}$ & & & $250 \mathrm{~s}$ \\
\hline 11 & & & & $3262 \mathrm{~m}$ & $3219 \mathrm{~m}$ & $400 \mathrm{sh}$ & $341 \mathrm{~s}$ & & & $253 \mathrm{~m}$ \\
\hline 12 & & & & $3265 \mathrm{~m}$ & $3220 \mathrm{~m}$ & $400 \mathrm{w}$ & $358 \mathrm{~s}$ & $290 \mathrm{~s}$ & $275 \mathrm{sh}$ & \\
\hline 13 & & & & $3270 \mathrm{~m}$ & $3224 \mathrm{~m}$ & $400 \mathrm{sh}$ & $347 \mathrm{~m}$ & & & $252 \mathrm{~m}$ \\
\hline 14 & $2090 \mathrm{~s}$ & overlapped & $477 \mathrm{~m}$ & $3260 \mathrm{vs}$ & $3220 \mathrm{vs}$ & $405 \mathrm{~m}$ & $365 \mathrm{~s}$ & $296 \mathrm{~s}$ & & \\
\hline 15 & $2090 \mathrm{~s}$ & $\begin{array}{l}\text { by bands of the } \\
\text { coordinated }\end{array}$ & $475 \mathrm{~m}$ & 3260 vs & 3220 vs & $400 \mathrm{~s}$ & $357 \mathrm{~s}$ & & & $<250$ \\
\hline 16 & $2080 \mathrm{~s}$ & aniline & $471 \mathrm{~m}$ & $3265 \mathrm{~s}$ & $3215 \mathrm{~s}$ & $395 \mathrm{~m}$ & $343 \mathrm{~s}$ & & & \\
\hline
\end{tabular}


in ethanol shows absorption maxima at 235 and $285 \mathrm{~nm}$. The spectra of the salts $\mathrm{AnHX}(\mathrm{X}=\mathrm{Cl}$, $\mathrm{Br}, \mathrm{I}, \mathrm{SCN}$ ) in ethanol also show regular maxima at 235 and $285 \mathrm{~nm}$ as well as succeeding absorptions in the form of shoulders at 255,260 and $265 \mathrm{~nm}$. These shoulders are due to the $\mathrm{AnH}^{+}$ion [19]. The maxima at 230 and $285 \mathrm{~nm}$ in the spectra of all aniline complexes obtained are due to electronic transitions of aniline, since they appear in the spectra of aniline, AnHX and coordination compounds of aniline [20]. The shoulder at $260 \mathrm{~nm}$ in the spectra of most aniline complexes is attributed to the $\mathrm{AnH}^{+}$ion [19].

Some characteristic and of diagnostic value IR frequencies $\left(\mathrm{cm}^{-1}\right)$ of the pyridine and aniline complexes are given in Tables II and III, respectively.

\section{Study of IR spectra of the pyridine complexes}

The two or three weak absorption bands in the region $3220-3100 \mathrm{~cm}^{-1}$ in the spectra of the pyridine complexes are due to the $\mathrm{PyH}^{+}$ion; their low intensity indicates that the $\mathrm{PyH}^{+}$ion is involved in hydrogen bridging [21]. The absence, also, of a strong broad band just below $3000 \mathrm{~cm}^{-1}$ excludes the presence of hydrogen bonding of the cationanion type, $\mathrm{N}^{+}-\mathrm{H}$-.. $\mathrm{X}^{-}[21]$; this is, of course, expected since, all halide ions and the thiocyanate are coordinated to $\mathrm{Zn}(\mathrm{II})$. The presence of $\mathrm{PyH}^{+}$ion in the molecules of the prepared complexes is clearly indicated by the absorption bands at 1630 , $1600,1525,1480,1325,1240$ and $1185 \mathrm{~cm}^{-1}[22,23]$.

The two absorption bands at 1570 and $1445 \mathrm{~cm}^{-1}$ as well as the strong ones at 1215, 1150, 1065, 1040, 1010, 750 and $695 \mathrm{~cm}^{-1}$ are due to coordinated pyridine [23]. The strong bands at 635 and $420 \mathrm{~cm}^{-1}$ are thought of being shifts of the bands at 604 (an in-plane ring deformation) and 405 (an out-of-plane ring deformation) $\mathrm{cm}^{-1}$ of free pyridine. The shifting of these bands to higher frequencies indicates coordinated pyridine $[22,24]$; consistent with this is the splitting of the band at $420 \mathrm{~cm}^{-1}$ in the spectra of the complexes $4,5,7$, and $8[22,24]$. The band at $635 \mathrm{~cm}^{-1}$ indicates a tetrahedral environment around $\mathrm{Zn}(\mathrm{II})[24,25]$. Absorption bands due to $\mathrm{Zn}-\mathrm{N}(\mathrm{Py})$ stretching vibrations appear below $250 \mathrm{~cm}^{-1}$ [24-26]

The strong bands in the region $325-290 \mathrm{~cm}^{-1}$ in the spectra of compounds $\mathbf{4}$ and $\mathbf{6}$ are attributed to $\mathrm{Zn}-\mathrm{Cl}$ terminal stretching vibrations, $v(\mathrm{Zn}-\mathrm{Cl})_{\mathrm{t}}$, since they are absent in the spectra of chlorine-free complexes; the frequencies of these bands clearly show that the structure of compounds 4 and $\mathbf{6}$ is tetrahedral $[24,26]$. Likewise, the strong bands at 251 and $255 \mathrm{~cm}^{-1}$ in the spectra of 5 and 7 , respectively are attributed to $v(\mathrm{Zn}-\mathrm{Br})_{\mathrm{t}}$ and their frequencies indicate a tetrahedral ligand arrangement around $\mathrm{Zn}(\mathrm{II})$ [24]. The $\mathrm{Zn}-\mathrm{I}$ stretching vibrations occur below $250 \mathrm{~cm}^{-1}$ [24].

The thiocyanate group has three diagnostic IR regions; C-N stretching $v(\mathrm{C}-\mathrm{N}), \mathrm{C}-\mathrm{S}$ stretching $v(\mathrm{C}-\mathrm{S})$ and NCS bending $\delta(\mathrm{NCS})$. The absorption bands in these regions are affected by different types of coordination. The absorption bands in the $\mathrm{CN}$ region appear at $2078 \mathrm{~cm}^{-1}$ in our spectra, a fact indicating the absence of bridged -SCN-groups [27] or free thiocyanate ions [28]. The C-S stretching region has been well dealt with in the chemical literature and has been used as a diagnostic region for the type of bonding of the thiocyanate group in the complexes. Turco and Pecile [29], studying IR spectra of complexes of known structure showed that the $v(\mathrm{C}-\mathrm{S})$ for the $\mathrm{S}$-bonded complexes occurs in the region $690-720 \mathrm{~cm}^{-1}$ and in the region 780 $860 \mathrm{~cm}^{-1}$ for the N-bonded ones. Since our spectra do not show absorption bands in the region 780$860 \mathrm{~cm}^{-1}$, the presence of $\mathrm{Zn}-\mathrm{NCS}$ bond is excluded. The assignment of $v(\mathrm{C}-\mathrm{S})$ in the region $690-720 \mathrm{~cm}^{-1}$ is impossible due to the simultaneous appearance of absorption bands of coordinated pyridine. The thiocyanate complexes show absorption bands in the region $440-400 \mathrm{~cm}^{-1}$ and the isothiocyanate ones in the region $490-450 \mathrm{~cm}^{-1}[30,31]$. In our case, the absence of a band in the region 490 $450 \mathrm{~cm}^{-1}$ excludes or rules out the presence of $\mathrm{Zn}-\mathrm{NCS}$ bond; in the region $440-400 \mathrm{~cm}^{-1}$ coordinated pyridine absorbs too.

Careful examination of the spectra of all prepared pyridine compounds clearly shows the absence of characteristic bands of free pyridine; hence these compounds contain no lattice pyridine [32].

\section{Study of IR spectra of the aniline complexes}

The spectra of all aniline complexes show two strong and broad bands at 2850 and $2580 \mathrm{~cm}^{-1}$, which are indicative of the $\mathrm{AnH}^{+}$ion involved in hydrogen bridging [33, 34]. The numerous weak bands in the region $2550-1650 \mathrm{~cm}^{-1}$ are mainly combination bands and overtones, some of which are due to the absorption of the $-\mathrm{NH}_{3}{ }^{+}$group $[33,35]$. The assignments in the region 1620 to $1500 \mathrm{~cm}^{-1}$ are difficult, since bands in this region 
are due to stretching vibrations of the benzene ring and bending vibrations of the $-\mathrm{NH}_{3}{ }^{+}$group [33]. The bands at $1600,1560,1515,1490,1465,1325$, $1290,1190,1175,1150,1110,1080,1025,1000,960$, $900,840,800,740,680,615,525$ and $380 \mathrm{~cm}^{-1}$ are due to $\mathrm{AnH}^{+}$ion since these appear also in the spectra of AnHX.

The spectrum also shows that aniline is coordinated to $\mathrm{Zn}(\mathrm{II})$. All spectra show two absorption bands in the region $3300-3200 \mathrm{~cm}^{-1}$. The band at the higher frequency is attributed to $-\mathrm{NH}_{2}$ antisymmetric stretching vibration while the one at the lower frequency to $-\mathrm{NH}_{2}$ symmetric stretching vibration. The frequencies of these bands (significantly lower than the corresponding in free aniline) indicate coordinated aniline [20,36]. The shifting and splitting of the bands at $740,680,615$ and $525 \mathrm{~cm}^{-1}$ show also coordinated aniline [37]. The two bands in the region $405-341 \mathrm{~cm}^{-1}$ of every spectrum are attributed to $\mathrm{Zn}-\mathrm{N}(\mathrm{An})$ stretching vibration or to vibration modes of aniline; the latter have, possibly, shifted or become infrared active upon the coordination of aniline [36, 38].

From the $v(\mathrm{Zn}-\mathrm{Cl})_{\mathrm{t}}$ and $v(\mathrm{Zn}-\mathrm{Br})_{\mathrm{t}}$ values (see Table III) it is concluded that the complexes $\mathbf{9}, \mathbf{1 0}$, $11,12,13$ and 14 have tetrahedral structure $[24,26$, $36,38]$. The absence of a band, due to $\mathrm{Zn}-\mathrm{Br}$ stretching vibration, above $250 \mathrm{~cm}^{-1}$ in the spectrum of compound $\mathbf{1 5}$, is reasonable, since this band often occurs slightly below $250 \mathrm{~cm}^{-1}$ for tetrahedral complexes of $\mathrm{Zn}(\mathrm{II})$ [26, 38].

The presence of the SCN group in the inner sphere of the aniline complexes is shown by the appearance of bands at 2090 and $475 \mathrm{~cm}^{-1}$.

The position of the $\mathrm{C}-\mathrm{N}$ stretching rules out the presence of the thiocyanate group in the ionic or bridged form. The position also of the NCS bending shows that the bonding of the thiocyanate group to $\mathrm{Zn}(\mathrm{II})$ is via the nitrogen atom.

Finally, the absence of lattice aniline is certain.

Correlation of the data regarding the stereochemistry of the pyridine and aniline complexes in the solid state

From the stability test it is concluded that the new compounds are complex compounds; the UV spectra also show that the aniline compounds contain the $\mathrm{AnH}^{+}$ion.

From the IR spectral analysis it is concluded that:

a) All compounds contain coordinated organic base.

b) In all complexes the $\mathrm{PyH}^{+}$and $\mathrm{AnH}^{+}$ions are involved in hydrogen bonding.

c) All complex anions are tetrahedral monomers.

d) None of these compounds contains lattice pyridine or aniline.

e) None of these compounds contains ionic or bridged thiocyanate. The pyridine complexes, containing the thiocyanate, are S-bonded, while the corresponding aniline complexes are $\mathrm{N}$ bonded.

On the basis of all these findings the following general structural formula is proposed for the new pyridine and aniline compounds:

$\left[\mathrm{ZnX}_{2} \mathrm{YB}\right]^{-}[\mathrm{B}-\mathrm{-H}-\mathrm{H}]^{+}$,

where $\mathrm{X}=\mathrm{Cl}, \mathrm{Br}, \mathrm{I} ; \mathrm{Y}=\mathrm{Br}, \mathrm{I}, \mathrm{SCN} ; \mathrm{B}=\mathrm{Py}, \mathrm{An}$.

The symbol ... represents a hydrogen bridge between the protonic hydrogen and two nitrogen atoms of two molecules of the organic base in the outer sphere of the complex; such a hydrogen bond has been observed in numerous compounds of complex haloacids $[4,5,7,8,37]$.

The authors wish to thank the National Hellenic Research Foundation for the financial support of part of this work. One of us (S.P.P.) is especially grateful to the said Foundation for the financial support he received for the duration of this research.
[1] A. G. Galinos, Bull. Soc. Chim. Fr. 1962, 284.

[2] A. G. Galinos, Angew. Chem. 69, 507 (1957).

[3] A. G. Galinos, J. Am. Chem. Soc. 82, 3032 (1960).

[4] A. G. Galinos, J. Inorg. Nucl. Chem. 19, 69 (1961).

[5] A. G. Galinos and S. P. Perlepes, Bull. Soc. Chim. Fr. 1979, 1-46.

[6] A. G. Galinos, J. Inorg. Nucl. Chem. 24, 1555 (1962).

[7] A. G. Galinos and Th. F. Zafiropoulos, Z. Naturforsch. 32 b, 1149 (1977).

[8] A. G. Galinos and Th. F. Zafiropoulos, Monatsh. Chem. 109, 1475 (1978).
[9] A. I. Vogel, Practical Organic Chemistry, 3rd ed., p. 163, Longmans, London 1967.

[10] K. K. Barnes and C. K. Mann, Anal. Chem. 36, 2502 (1964).

[11] A. I. Vogel, Quantitative Inorganic Analysis, 3rd ed., (a) p. 933 , (b) pp. 433, 434, (c) pp. 264-268, (d) pp. 568, 569, Longmans, London 1961.

[12] W. E. Bazzelle, Analyt. Chim. Acta 54, 29 (1971).

[13] J. S. Fritz, Acid-Base Titrations in Nonaqueous Solvents, pp. 122-127, Allyn and Bacon Inc., Boston 1973. 
[14] A. R. Nicholson and G. J. Sutton, Aust. J. Chem. 22, 1543 (1969).

[15] C. R. Noller, Chemistry of Organic Compounds, 3rd ed., pp. 160, 161, Saunders, Philadelphia 1965.

[16] M. Bressan, R. Ettorre, and P. Rigo, Inorg. Chim. Acta 24, L 57 (1977).

[17] C. N. R. Rao, Ultra-Violet and Visible Spectroscopy, 2nd ed., pp. 15-17, 60, 77-79, Butterworths, London 1967.

[18] H. P. Stephenson, J. Chem. Phys. 22, 1077 (1954).

[19] S. F. Dyke, A. J. Floyd, M. Sainsbury, and R. S. Theobald, Organic Spectroscopy, An Introduction, p. 37, Penguin Books Inc., Baltimore 1971.

[20] C. H. Misra, S. S. Parmar, and S. N. Shukla, J. Inorg. Nucl. Chem. 28, 147 (1966).

[21] R. H. Nuttall, D. W. A. Sharp, and T. C. Wad. dington, J. Chem. Soc. 1960, 4965.

[22] N. S. Gill, R. H. Nuttall, D. E. Scaife, and D. W. A. Sharp, J. Inorg. Nucl. Chem. 18, 79 (1961).

[23] P. C. H. Mitchell, J. Inorg. Nucl. Chem. 21, 382 (1961).

[24] R. J. H. Clark and C. S. Williams, Inorg. Chem. 4, 350 (1965).

[25] C. W. Frank and L. B. Rogers, Inorg. Chem. 5, 615 (1966).
[26] J. Bradbury, K. P. Forest, R. H. Nuttall, and D. W. A. Sharp, Spectrochim. Acta, Part A 23, 2701 (1967).

[27] J. Chatt and L. A. Duncanson, Nature (London) 178, 997 (1956).

[28] J. L. Burmeister and F. Basolo, Inorg. Chem. 3, 1587 (1964).

[29] A. Turco and C. Pecile, Nature (London) 191, 66 (1961).

[30] J. Lewis, R. S. Nyholm, and P. W. Smith, J. Chem. Soc. 1961, 4590 .

[31] I. Bertini and A. Sabatini, Inorg. Chem. 5, 1025 (1966).

[32] D. P. Graddon, K. B. Heng, and E. C. Watton, Aust. J. Chem. 19, 1801 (1966).

[33] B. Chenon and C. Sandorfy, Can. J. Chem. 36, 1181 (1958).

[34] C. Brissette and C. Sandorfy, Can. J. Chem. 38, 34 (1960).

[35] J. C. Evans, Spectrochim. Acta 16, 428 (1960).

[36] M. A. J. Jungbauer and C. Curran, Spectrochim. Acta 21, 641 (1965).

[37] A. G. Galinos and D. M. Kaminaris, Chimika Chronika (New Series) 2, 59 (1973).

[38] I. S. Ahuja, D. H. Brown, R. H. Nuttall, and D. W. A. Sharp, J. Inorg. Nucl. Chem. 27, 1105 (1965). 